\title{
Effectiveness of Plyometric Exercises to Improve Speed and Agility in Young Beginner Swimmers: A Randomized Control Trial
}

\author{
Vidhi Soni $^{1}$, Nidhi Vedawala ${ }^{2}$ \\ ${ }^{1}$ Intern, ${ }^{2}$ Tutor, Nootan College of Physiotherapy, Sankalchand Patel University, Visnagar, Gujarat, India \\ Corresponding Author: Nidhi Vedawala
}

DOI: https://doi.org/10.52403/ijrr.20220311

\begin{abstract}
Background: Swimming is a great sport enjoyed by all age group at all level of ability that combines upper and lower limb strength. It could be a recreational and extremely competitive sport which requires a high level of training and performance. There is various power and stamina based exercise in order to increase performance of athlete as per their physical properties. Plyometric exercise, as it is a type of exercise which helps work every muscle of an athlete used as an effective method in increasing power and speed capacity of athlete. It involves quick, explosive movement designed to increase speed, agility, balance, coordination and power.

Objective: The aim of the study is to analyze the effects of plyometric exercises to get better speed and agility improvement in young beginner swimmers.

Study design: A randomized controlled trial

Methods: In a 6-week study, 30 young beginner male swimmers were studied. They were divided into 2 groups by a simple random sampling (Lottery method); Group A: Plyometric exercise program and Group B: Control. Pre and post treatment data was collected and analyzed using SPSS 22.0. Paired and unpaired $t$ test were used to find out the significance of the treatment.

Results: A significant improvement in Speed and Agility $(p<0.05)$ after the treatment were found. Greater statistically significant improvement was seen in Group A as compared to Group B.
\end{abstract}

Conclusion: The study concluded that Plyometric exercises are effective to improve speed and agility in young beginner swimmers.

Keywords: Plyometric, Speed, Agility, Swimming, Beginners

\section{CTRI NUMBER: CTRI/2021/11/038184}

\section{INTRODUCTION}

Some players are seeking to win a competition or improve previous performance. So, training is a process by which a player is prepared for the highest level of performance possible. When we are talking about physical performance, it means the performance of our body to sustain our daily routine. The intent of the training is to increase the player's ability and work capacity to optimize the player's performance. ${ }^{(1)}$ Swimming is a great sport enjoyed by all age groups at all level of ability that combines upper and lower limb strength .So that it demands a high level of training commitment from a young age. ${ }^{(2)}$ There are four styles of swimming freestyle, backstroke, butterfly and breaststroke. Swimming is a sport done in water through the synchronized movement of the limbs and the body. ${ }^{(3)}$ The Performance in swimming depends on generating propel power and minimizing the resistance to move into the water. ${ }^{(4)}$ It could be a recreational and extremely competitive sport which require a high level of training and performance that is why overuse of muscles lead to injuries to swimmers. Prevalence of 
injuries in the swimmers is more frequent in the shoulder area $37 \%$ than knee area with $28 \%$ and foot \& ankle with $19 \%$ rate. ${ }^{(5)}$ There is various power and stamina based exercise in order to increase the performance of athlete as per their physical properties. Plyometric exercise, as it is a type of exercise that helps work every muscle of an athlete used as an effective method in increasing the power and speed capacity of an athlete. ${ }^{(6)}$ Plyometric training (PT) was introduced by Verkoshanski as a training mode to enhance explosive strength in exercise. ${ }^{(7)}$ It involves quick, explosive movement designed to increase speed, agility, balance, coordination and power. The goal of the exercise is to decrease the amount of time in between these movements. So an athlete can become faster and more powerful.

It is a powerful movement involving an eccentric contraction, followed immediately by an explosive concentric contraction This is accomplished through the stretch-shortening cycle or an eccentricconcentric coupling phase. ${ }^{(8-11)}$

Plyometrics involve both lower extremity (LE) and upper extremity (UE) as a part of functional movement patterns and skills when performing the sport. It is a stretch shortening cycle (SSC) by using a lengthening movement (eccentric) which is quickly followed by a shortening movement (concentric). ${ }^{(11)}$ Three phases of plyometric exercise:1]The eccentric phase: The first stage of a plyometric movement can be classified as the eccentric phase, but it has also been called the deceleration, loading, yielding, countermovement, or cocking phase. This phase increases muscle spindle activity by pre-stretching the muscle before activation. 2] The amortization phase: This phase involves dynamic stabilization and is the time between the end of the eccentric contraction and the initiation of the concentric contraction (the unloading or force production phase). A prolonged amortization phase results in less-thanoptimum neuromuscular efficiency from a loss of elastic potential energy. A rapid switch from an eccentric contraction to a concentric contraction leads to a more powerful response.3] The concentric phase: The concentric phase: occurs immediately after the amortization phase and involves a concentric contraction resulting in enhanced muscular performance following the eccentric phase of muscle contraction. This occurs secondary to enhanced summation and reutilization of elastic potential energy, muscle potentiation, and contribution of the myotatic stretch reflex. Some plyometric exercises: Box jump-up, Squat jump, Lunges jump/split squats, Butt kicks, Tuck jumps,Lateral, front-back hops, Depth ,drop jumps, Hurdle jump and many more exercises. ${ }^{(11-13)}$

Some studies suggest an effect of plyometric training in different types of sports. Although there was some study concluded plyometric effects on speed, balance, strength, agility, endurance in different sports and different types of athletes. So need of the study is to find out the effect of plyometric exercise on speed and agility specifically in the young beginner group. The aim of the study is to analyze the effects of plyometric exercises to get better speed and agility improvement in young beginner swimmers.

Hypothesis: Null hypothesis [Ho]: There will be no significant effect of plyometrics on speed and agility in young beginner

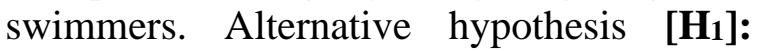
There will be significant effect of plyometrics on speed and agility in young beginner swimmers.

\section{REVIEW OF LITERATURE}

Sajjan pal,et.al (2020)conducted an experimental study on 120 subjects on"effects of plyometrics and pilates training on physical fitness skill of male karate athletes" and they concluded that plyometric training have more positive effect on agility, power and speed in karate athelets.

Mr. R. Prathap (2011) conducted an experimental study on "A study on the 
effectiveness of a six week plyometric training program on agility" and concluded that the significant improvement in agility performance was obtained in the experimental group in corporate with six week plyometric training program for male athletes.

Marco beato, mattia bianchi, et.al (2017) conducted randomized group trial on "effects of plyometric and directional training on speed and jump performance in elite youth soccer players" on 20 subjects for 6 weeks and this study showed that short-term protocols are important and able to give meaningful improvements on power and speed parameters in a specific soccer population.

Roshani S. Patel, Amit Sharma, et.al (2019) conducted RCT on" Effect of Strength Training on Performance of Young Competitive swimmers" on 60 subjects for 6 weeks and concluded that There is a significant improvement on the performance of young competitive swimmers with specific exercise regimes to improve stroke rate and $50 \mathrm{~m}$ kicking speed that may be increased swimming performance in freestyle.

\section{MATERIALS AND METHODS}

Research design: A randomized controlled trial

Sample design: Simple Random Sampling (Lottery method)

Study population: Young beginner swimmers

Sample size: 30 Participants Group A: 15subjects (Plyometric Exercise Program) Group B: 15subjects (Control Group)

Study setting: Sardar Patel Ramat Gamat Sankul Gymkhana, Patan, Gujarat.

Study duration: 6 months (September 2021 to February 2022).

Treatment duration: 6 Weeks

\section{Inclusion criteria}

1. Male

2. Beginner participants (who have been joined swimming from last 1 week to 1 month)

3. Age: 18 to 25

4. Normal BMI $\left(18.5-24.9 \mathrm{~kg} / \mathrm{m}^{2}\right)$

5. Participants who are willing to be part of study.

\section{Exclusion criteria}

1. Participants with the age group of below 18 or above 25 years.

2. Any pain, inflammation, acute/subacute sprain or strain

3. Any joint instability

4. Any muscle contractures or deformity.

\section{Randomization:}

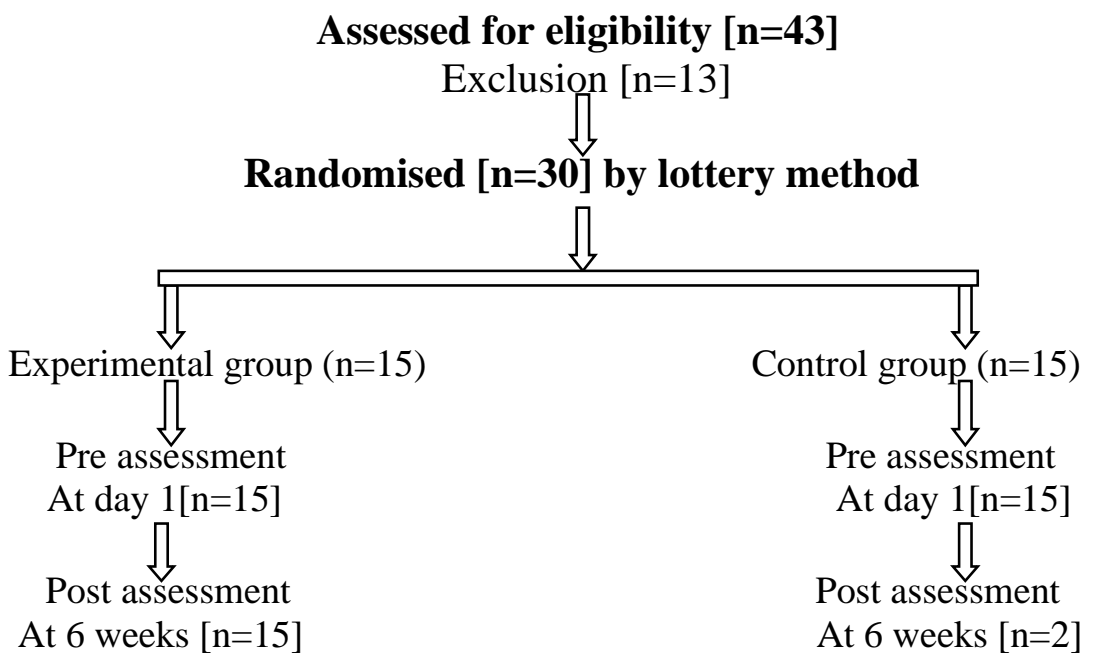


Vidhi Soni et.al. Effectiveness of plyometric exercises to improve speed and agility in young beginner swimmers: a randomized control trial

Ethical approval was generated from the Institutional ethical committee and the participants gave an informed written consent signed. All thirty participants' demographic data were recorded. The participants were divided into two groups i.e. Group A and Group B by simple randomize sampling by lottery method.

Group A will be given plyometric exercise program \& Group B will continue their regular general body exercises, warm up and cool down as they are in the control group.

\section{INTERVENTION DESIGN [For 6 weeks (5 days/week)]}

\begin{tabular}{|c|c|c|c|c|c|}
\hline WEEK 1 & WEEK 2 & WEEK 3 & WEEK 4 & WEEK 5 & WEEK 6 \\
\hline $\begin{array}{c}\text { standing jump and reach } \\
\text { (10 rep } 2 \text { sets })\end{array}$ & $\begin{array}{l}\text { Long jump } \\
\text { (10 rep } 3 \text { sets) }\end{array}$ & $\begin{array}{l}\text { Lateral cone hopes } \\
\text { (15 rep } 3 \text { sets })\end{array}$ & $\begin{array}{c}\text { Drop jump } \\
(15 \text { rep } 3 \text { sets })\end{array}$ & $\begin{array}{c}\text { Lateral jump over } \\
\text { barrier ( } 15 \text { rep } 3 \text { sets })\end{array}$ & $\begin{array}{l}\text { Diagonal cone hops } \\
\text { (20 rep } 3 \text { sets) }\end{array}$ \\
\hline $\begin{array}{c}\text { Forward and backward } \\
\text { ankle hops (10 rep } 2 \text { sets) }\end{array}$ & $\begin{array}{l}\text { Snowboard hops } \\
\text { (10 rep } 2 \text { sets) }\end{array}$ & $\begin{array}{l}\text { Butt kick jump } \\
\text { (20 rep } 3 \text { sets) }\end{array}$ & $\begin{array}{l}\text { Depth jump } \\
\text { (15 rep } 3 \text { sets) }\end{array}$ & $\begin{array}{l}\text { Diagonal cone hops } \\
\text { (15 rep } 2 \text { sets) }\end{array}$ & $\begin{array}{c}\text { Box jump } \\
(15 \text { rep } 3 \text { sets })\end{array}$ \\
\hline $\begin{array}{l}\text { Lateral ankle hops } \\
\text { (10 rep } 2 \text { sets) }\end{array}$ & $\begin{array}{l}\text { Lateral cone hops } \\
\text { (10 rep } 2 \text { sets) }\end{array}$ & $\begin{array}{c}\text { Drop jump } \\
\text { (10 rep } 2 \text { sets) }\end{array}$ & $\begin{array}{c}\text { Lateral jump } \\
\text { over barrier } \\
\text { (10 rep } 2 \text { sets })\end{array}$ & $\begin{array}{c}\text { Plyo jacks } \\
\text { (20rep } 3 \text { sets) }\end{array}$ & $\begin{array}{l}\text { Explosive step up } \\
\text { (15 rep } 3 \text { sets) }\end{array}$ \\
\hline $\begin{array}{c}\text { Split squats } \\
(10 \text { rep } 2 \text { sets })\end{array}$ & $\begin{array}{l}\text { Butt kick jump } \\
\text { (15 rep 2sets) }\end{array}$ & $\begin{array}{l}\text { Depth jump } \\
\text { (10 rep } 2 \text { sets) }\end{array}$ & $\begin{array}{c}\text { Plyo jacks } \\
(15 \text { rep } 2 \text { sets })\end{array}$ & $\begin{array}{c}\text { Box jump } \\
\text { (10 rep } 2 \text { sets })\end{array}$ & $\begin{array}{l}\text { Hexagonal drill } \\
\text { (15 rep } 3 \text { sets })\end{array}$ \\
\hline
\end{tabular}

Data collection procedure: Data will be collected at baseline and at the end of 6 week straining. Follow up will be taken at 6 months. The participants underwent a detailed pre evaluated assessment which obtained information about demographic data, examination and functional outcomes.

Outcome measures: $30 \mathrm{~m}$ Dash test

Illinois Agility Test

\section{Statistical Analysis}

The data were tabulated and participated to statistical analysis using SPSS 22.0 software for windows and analysed with paired $t$ test and unpaired $t$ test. After treatment the result showed a significant improvement $(\mathrm{p}<0.05)$ in terms of increase speed and agility.

\section{RESULTS}

Table no.2: Intragroup comparison of pre -post treatment of both groups

\begin{tabular}{|c|c|c|c|c|c|c|c|c|c|}
\hline \multirow[b]{2}{*}{ Outcome } & \multicolumn{4}{|c|}{ Group A } & \multicolumn{5}{|c|}{ Group B } \\
\hline & $\begin{array}{c}\text { Pre- } \\
\text { Treatment } \\
\text { Mean SD }\end{array}$ & $\begin{array}{c}\text { Post- } \\
\text { Treatment } \\
\text { Mean SD }\end{array}$ & $\begin{array}{c}c t \\
\text { value }\end{array}$ & $\begin{array}{c}\text { p- } \\
\text { value }\end{array}$ & Outcome & $\begin{array}{c}\text { Pre- } \\
\text { Treatment } \\
\text { Mean SD }\end{array}$ & $\begin{array}{c}\text { Post- } \\
\text { Treatment } \\
\text { Mean SD }\end{array}$ & $\begin{array}{c}c \\
\mathbf{t} \\
\text { value }\end{array}$ & $\begin{array}{c}\text { p- } \\
\text { value }\end{array}$ \\
\hline $\begin{array}{l}30 \mathrm{~m} \text { Dash } \\
\text { Test Score }\end{array}$ & $5.46 \pm 0.89$ & $4.24 \pm 0.20$ & 4.96 & 0.00 & $\begin{array}{l}30 \mathrm{~m} \text { Dash } \\
\text { Test Score }\end{array}$ & $6.12 \pm 1.01$ & $6.19 \pm 1.17$ & -0.56 & 0.58 \\
\hline $\begin{array}{l}\text { Illinois Agility } \\
\text { Test }\end{array}$ & $19.52 \pm 0.91$ & $16.74 \pm 0.95$ & 7.01 & 0.00 & $\begin{array}{l}\text { Illinois Agility } \\
\text { Test }\end{array}$ & $20.41 \pm 1.81$ & $20.24 \pm 1.76$ & 1.78 & 0.96 \\
\hline
\end{tabular}
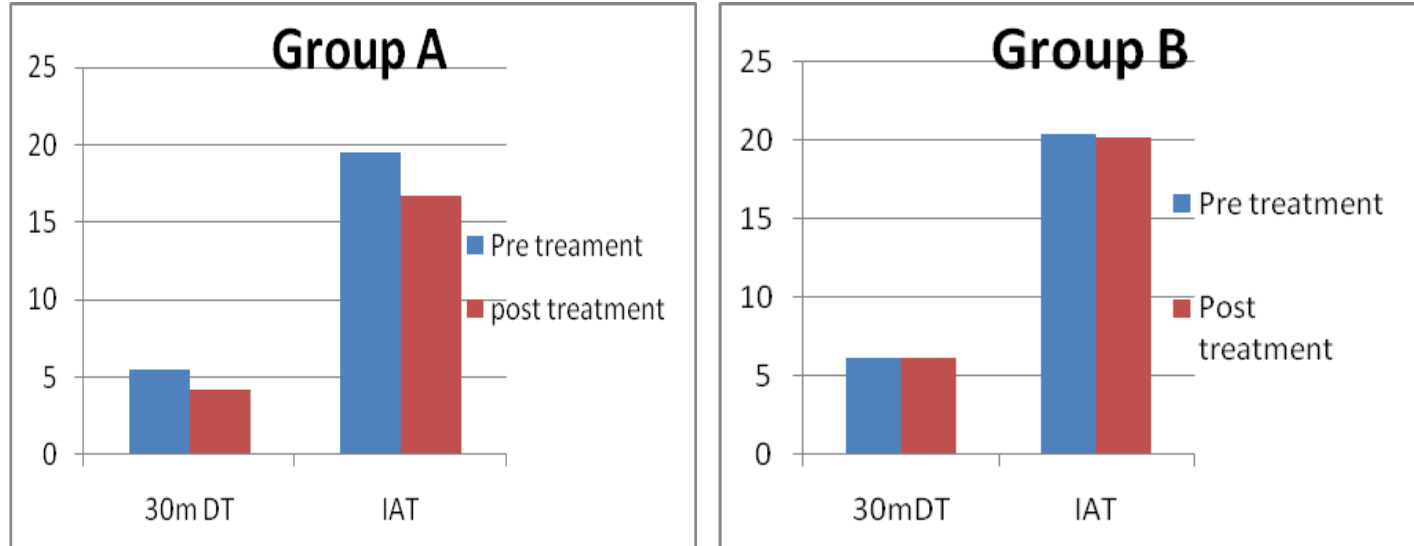

[Graph-Intragroup comparison of pre-post treatment of both groups] 
Pre and post treatment data of participants of both groups were noted. All statistical analysis was done using SPSS 22.0 software. Descriptive analysis was obtained by using Mean \& SD. The intergroup comparison between group A and B of prepost treatment of outcomes were done by unpaired $t$ test. The intragroup comparison between both group of pre post treatment of outcomes were done by paired $t$ test.

\section{DISCUSSION}

The aim of the study was to improve speed and agility in young and beginner swimmers. This study carried out using plyometric exercises on the 30 subjects as per inclusion and exclusion criteria and divided into 2 groups. Plyometric exercises were given for 6 weeks to improve speed and agility in young beginner swimmers. The result of the present study demonstrated that improvement in speed and agility after 6 weeks of plyometric exercises in group A but there was no significant improvement of speed and agility in Group B. So, the null hypothesis is rejected and the experimental hypothesis is accepted here.

One of the important factors for swimmers that they need lower body strength that helps to propel forward along with stabilizing the trunk and streamlining the body. ${ }^{(14)}$ As swimming needs power and stamina it would be effective some type of exercise. One of those activities is Plyometric exercise which is based on to improve speed, agility, coordination and balance, strength in athletes.

Plyometric exercises always follow the same specific sequence: 1) landing phase 2) An amortization phase. 3) Take off. The landing phase starts as soon as the muscles start to experience an eccentric contraction. Inadequate strength will result in a slow rate of stretch and less activation of the stretch reflex. The amortization phase, the time on the ground, is the most important part of a plyometric exercise. It represents the turn around time from landing to take off and is crucial for power development. If the amortization phase is too long, the stretch reflex is lost and there is no plyometric effect. The take off is the concentric contraction that follows the landing. During this phase the stored elastic energy is used to increase jump height and explosive power. ${ }^{(15)}$

The reason behind the improvement in speed and agility can be because of strength training there was an increase in muscle force of slow and fast twitch muscle fibers that lead to improvement in strength and produce maximal and explosive forces are required for swimming performance.

In this study subjects were divided into two groups (A \& B). Group A was interventional group in which plyometric exercises were given for 6 weeks to participants. Group B was control group. In this study $30 \mathrm{~m}$ DT and IAT were used as outcome measures. Though a significant improvement was found after treatment period in group A. Group A showed greater improvement in 30DT and IAT score.(p value $<0.05$ ). Thus this study is fail to reject null hypothesis.

\section{Limitation}

1. Long term follow up was not taken.

2. The study includes treatment period of 6 weeks only.

3. The study involves small sample size.

4. The study includes only male because interpretation of outcomes is different for female.

\section{Suggestions and recommendations}

1. The study can be done with long term follow up.

2. The study can be done with longer treatment duration.

3. The study can be revised involving a larger sample size.

4. Further studies can be done using the same intervention procedures for females only or both males and females.

\section{CONCLUSION}

There is a significant improvement in outcome measures in Group A. So the current study concludes that there is significant improvement in speed and agility 
in young beginner swimmers in the experimental group (Group A) after 6 weeks of the plyometric exercise program.

\section{Acknowledgement}

A successful outcome in any research Endeavour attributes itself to the selfless guidance of the mentor. I would like to express my deep appreciation and gratitude to my guide Dr. Nidhi Vedawala. I am so fortunate that I got to work under the guidance of such a person who gave me valuable advices, intellectual guidance and all the help that I needed in making of this dissertation. I am thankful to her for giving me the opportunity to explore new things on my own and at the same time guiding me and making me understand things whenever I was wrong. I thank her for her constant motivation; patience and support that helped me complete this dissertation. Her consistent efforts to make me use proper sentences, careful reading and revising the dissertation and her advice in statistical analysis and data presentation has helped me to learn a lot of things.

My heartful thanks to my parents Mr. Nilesh Soni and Mrs. HinaSoni, my loving brother Hemal Soni and my family members for their interest in my academic excellence, for their constant love, encouragement and providing supportive and cheerful environment which made this work easy. I am also thankful to Mehta Fitness Center, Patan for the support and help. I am also thankful to my friends for their support, help and constant motivation for completion of this work.

Lastly I honor all the participants of the study for participating in this study and helping me.

\section{Conflict of Interest: None}

\section{Source of Funding: None}

\section{REFERENCES}

1. Hardeep Kaur Saini, Relationship of plyometric and circuit training with explosive strength and agility of Punjab state basketball players; International
Journal of Physiology, Nutrition and Physical Education.2019, 4(1): 36-38.

2. Nugent F, Comyns T, Warrington G. Quality Versus Quantity Debate in Swimming: Perceptions and Training practices of Expert Swimming Coaches. Journal of Human Kinetics. 2017;57(1):147158.

3. Rajesh Kumar. A Study on the Effect of Plyometric Exercises for Development of Speed in 50 M Back Stroke in Swimming. International. Journal of physical education. sports and health 2014:1(1)05-07.

4. Schneider P, Meyer F. Anthropometric and muscle strength evaluation in prepubescent and pubescent swimmer boys and girls. RevistaBrasileira de Medicina do Esporte. 2005;11(4):209-213.

5. Adiele D. Prevalence of Musculoskeletal Injuries in Males and Females Practicing Swimming from Higher School of Zimbabwe. American Journal of Sports Science. 2018;6(1):8.

6. Gencer Y, Igdir E, Sahin S, Eris F. Effects of 8 Weeks of Plyometric Exercise on Certain Physiological Parameters and Performance of Swimmers. Journal of Education and Training Studies. 2018; 6(7): 49.

7. Verkoshanski, Y. Are depth jumps useful? Track and Field. 12, 9. Translated from: Yessis, Rev Soviet Phys Educ Sport 4: 2835, 1968

8. Bosco C, Viitasalo J, Komi P, Luhtanen P. Combined effect of elastic energy and myoelectrical potentiation during stretchshortening cycle exercise. Acta Physiologica Scandinavica. 1982; 114(4): 557-565.

9. Verhoshanski Y. Depth jumping in the training of jumpers. Track Technique 1983; 51:1618-619. 23.

10. Wilt F. Plyometrics, what it is and how it works. Athl J 1975;55:76-90

11. Rodrigo Cañas-Jamett, Plyometric Training Improves Swimming Performance In Recreationally-Trained Swimmers, Revista Brasileira de Medicina do Esporte; 2020;26 (5): 436-440

12. Mark A. Booth and Rhonda Orr, Effects of Plyometric Training on Sports Performance, National Strength and Conditioning Association, 2016;38(1):30-37

13. Vescovi J, Canavan P, Hasson S. Effects of a plyometric program on vertical landing 
Vidhi Soni et.al. Effectiveness of plyometric exercises to improve speed and agility in young beginner swimmers: a randomized control trial

force and jumping performance in college women. Physical Therapy in Sport. 2008; 9 (4):185-192.

14. Lawrence, L. The importance of the freestyle leg kick. Int Swimmer 5: 11-12, 1969.

15. Ed McNeely, MS, Introduction to Plyometrics: Converting Strength to Power, NSCA's Performance Training Journal; 6(5)19-22.
How to cite this article: Vidhi Soni, Nidhi Vedawala. Effectiveness of plyometric exercises to improve speed and agility in young beginner swimmers: a randomized control trial. International Journal of Research and Review. 2022; 9(3): 89-95. DOI: https://doi.org/ 10.52403/ijrr.20220311 